Article

\title{
Preventive Effect of Anji White Tea Flavonoids on Alcohol-Induced Gastric Injury through Their Antioxidant Effects in Kunming Mice
}

\author{
Bihui Liu ${ }^{1,2,3,4,+}$, Xingxing Feng ${ }^{4,+}$, Jing Zhang ${ }^{5,+}$, Yang Wei ${ }^{1,2,3}$ and Xin Zhao ${ }^{1,2,3, *(D)}$ \\ 1 Chongqing Collaborative Innovation Center for Functional Food, Chongqing University of Education, \\ Chongqing 400067, China; liubh@foods.ac.cn (B.L.); grace951006@163.com (Y.W.) \\ 2 Chongqing Engineering Research Center of Functional Food, Chongqing University of Education, \\ Chongqing 400067, China \\ 3 Chongqing Engineering Laboratory for Research and Development of Functional Food, \\ Chongqing University of Education, Chongqing 400067, China \\ 4 College of Biological and Chemical Engineering, Chongqing University of Education, \\ Chongqing 400067, China; fengxx@foods.ac.cn \\ 5 Environment and Quality Inspection College, Chongqing Chemical Industry Vocational College, \\ Chongqing 401228, China; zhangjing@foods.ac.cn \\ * Correspondence: zhaoxin@cque.edu.cn; Tel.: +86-23-6265-3650 \\ + These authors contributed equally to this work.
}

Received: 27 February 2019; Accepted: 1 April 2019; Published: 4 April 2019

\begin{abstract}
Anji white tea (Camellia sinensis) is a traditional Chinese tea beverage, which is classified as green tea and contains an abundant amount of flavonoids. In this study, the preventive effect of Anji white tea flavonoids (AJWTFs) on ethanol/hydrochloric acid-induced gastric injury in mice was evaluated. The serum and gastric tissues of mice were analyzed using a biochemical kit and by quantitative polymerase chain reaction (qPCR). Observation of the appearance of the stomach indicated that AJWTFs could effectively reduce the area of gastric injury caused by ethanol/hydrochloric acid, and the inhibition rate of AJWTF on gastric injury increased with an increase in AJWTF concentration. The Anji white tea flavonoids could also reduce the volume and $\mathrm{pH}$ of gastric juice in mice with gastric injury. Biochemical results showed that AJWTFs could increase the superoxide dismutase (SOD) and glutathione (GSH) activities, as well as decrease the malondialdehyde (MDA) level, in the serum and liver of mice with gastric injury. Pathological observation confirmed that AJWTFs could inhibit the tissue damage caused by ethanol/hydrochloric acid in the stomach of mice. Further qPCR experiments also showed that AJWTFs could inhibit the decreases in neuronal nitric oxide synthase (nNOS), endothelial nitric oxide synthase (eNOS), copper / zinc superoxide dismutase ( $\mathrm{Cu} / \mathrm{Zn}-\mathrm{SOD})$, manganese superoxide dismutase (Mn-SOD), catalase (CAT), and the increase in inducible nitric oxide synthase (iNOS) expression in the gastric tissue of mice caused by gastric injury. As observed, AJWTFs exerted a good preventive effect on alcohol-induced gastric injury in mice induced by ethanol/hydrochloric acid, and the effect is close to that of ranitidine. Anji white tea flavonoids present good antioxidant effect, which allows them to effectively prevent alcoholic gastric injury and be used as biologically active substances with a broad range of applications.
\end{abstract}

Keywords: Anji white tea; flavonoid; alcoholic gastric injury; messenger RNA expression; oxidation

\section{Introduction}

Alcoholic gastric injury is a gastric mucosal injury caused by excessive drinking, which often clinically manifests as gastritis. Ethanol can directly damage gastric epithelial cells and submucosal 
vessels [1], causing direct injury to the epithelium of the gastric mucosa. Ethanol directly damages the epithelial cells in the gastric mucosa, destroying the barrier of the gastric mucosa. Hydrophobic alkyl groups and hydrophilic hydroxyl groups of ethanol molecules can directly destroy the defense system of the gastric mucosa, rendering the gastric mucosa vulnerable to various digestive enzymes, bile, and gastric acid. This susceptibility leads to $\mathrm{H}^{+}$antidiffusion, thereby aggravating the damage to the gastric mucosa. Ethanol can cause injuries to the submucosal vascular endothelium, hemangiectasia, small blood vessel bursts, submucosal hemorrhage, and other changes, further destroying the mucosal barrier. Alcohol can also cause neutrophils to infiltrate and further aggravate mucosal damage as a result of numerous inflammatory mediators produced by mucosal epithelial and vascular endothelial damage [2]. In addition, increased ethanol concentration exerts a strong stimulating effect on the gastric mucosa and can cause necrosis of mucosal epithelial cells [3]. The frequent occurrence of gastritis, gastric ulcer, gastric perforation, gastric bleeding, and other gastric diseases recently directed the attention toward alcoholic gastric injury. In addition to drug treatment, the preventive effect and application of bioactive substances on alcoholic gastric injury also has research interest.

White tea is a kind of micro-fermented tea, which is one of the six major tea categories in China. Most white tea is unique, mainly because the production process is very simple, mainly including four processes of picking, spreading, withering, and drying. Anji white tea (AJWT) is mainly produced in Anji County, Zhejiang Province, China. It is called white tea because its raw tea leaves are white as a result of chlorophyll deficiency, which is attributed to variation. However, AJWT varies from other white tea in its processing technology. It is non-fermented tea and is classified as green tea; it is made through six processes (picking, spreading, killing, sorting, drying, and preservation), unlike other white tea [4]. Many bioactive compounds are found in flavonoids, which can prevent and treat cardiovascular and cerebrovascular diseases by reducing the fragility of blood vessels, improving the permeability of blood vessels, reducing blood lipids and cholesterol, preventing and treating hypertension, cerebral hemorrhage, coronary heart disease, and angina pectoris, expanding coronary vessels, and increasing coronary flow [5,6]. Simultaneously, flavonoids protect and detoxify the liver and act as an antifungal [7]. Most physiological activities of plant flavonoids are based on their antioxidant effects [8]. In vitro studies showed that Anji white tea flavonoids (AJWTFs) exert scavenging effects on superoxide anion radicals $\left(\mathrm{O}_{2}{ }^{\bullet-}\right)$, hydroxyl radicals $\left({ }^{\bullet} \mathrm{OH}\right), 2$,2-diphenyl-1-picrylhydrazyl (DPPH), and hydrogen peroxide [9]. Therefore, AJWTFs are also substances with antioxidant activity, which may benefit and protect the body. Several studies also indicated that flavonoids from natural plants exert a certain inhibitory effect on gastric injury [10-12]. Flavonoids in natural plants can inhibit gastric injury through their antioxidant effects [11,12]. There are few studies on AJWTFs, whereby only in vitro studies showed that AJWTFs have the ability to scavenge superoxide anion free radicals, hydroxyl free radicals, hydrogen peroxide, and DPPH free radicals [13]. Accordingly, the protective effect of AJWTFs on the stomach needs to be investigated.

Few studies on AJWTFs were conducted, and the understanding and application of active substances in this natural beverage are inadequate. In this study, a mouse model of alcoholic gastric injury was established to observe the preventive effect of AJWTFs on alcoholic gastric injury in animals; in addition, the mechanism of action of AJWTFs on oxidative stress induced by gastric injury in mice was observed. Anji white tea is currently only used as a common beverage. Serum and tissues in mice were observed by biochemical detection and based on experiments in molecular biology. In accordance with the results of this study, ideas are proposed for the further application of AJWT, particularly the mechanism of the AJWTF extract, to accumulate theoretical evidence of the application of AJWTFs as functional foods with biological activity. This study only focused on experimental animals; regardless, it lays the foundation for further clinical research on AJWTF. 


\section{Materials and Methods}

\subsection{Extraction of Anji White Tea Flavonoids}

Anji white tea leaves was picked in Anji County, Zhejiang Province, China in mid-March 2018. Tea canopy surface reached 10-15 standard buds per square meter for picking. Tea trees were picked one leaf per bud according to the requirements. Up to $1 \mathrm{~kg}$ of freeze-dried AJWT leaf samples was weighed and powdered. Anji white tea leaves powders were divided into 10 parts on average. One liter of ethanol solution with a concentration of $70 \%(\mathrm{v} / \mathrm{v})$ was added to each part. After extraction for $4 \mathrm{~h}$ at $70{ }^{\circ} \mathrm{C}$ in a water bath, 10 filtrates were collected and filtered by diatomite to remove lipid-soluble impurities. All extracts were collected again and then added to the column containing ADS-17 resin. AJWTF were adsorbed by the resin. Subsequently, 90\% (v/v) ethanol was used to elute the resin and dissolve the adsorbed flavanone in ethanol. The AJWTF extract was ultimately obtained by steam-drying ethanol [14].

\subsection{Determination of Anji White Tea Flavonoid Content}

A specific amount $(10 \mathrm{mg})$ of rutin standard (Hefei Bomei Biotechnology Co., Ltd., Hefei, China) was added into a 25-mL volumetric flask; $10 \mathrm{~mL}$ of $(v / v) 90 \%$ ethanol was added, followed by $0.75 \mathrm{~mL}$ of $5 \% \mathrm{NaNO}_{2}$ solution, $0.75 \mathrm{~mL}$ of $10 \% \mathrm{Al}\left(\mathrm{NO}_{3}\right)_{3}$ solution, and $10 \mathrm{~mL}$ of $4 \% \mathrm{NaOH}$ solution. A rutin standard solution in 90\% ethanol was ultimately prepared, and 10, 20, 30, 40, and $50 \mu \mathrm{g} / \mathrm{mL}$ rutin concentrations were determined at $500 \mathrm{~nm}$ (Evolution 300 ultraviolet spectrophotometer, Thermo Fisher Scientific, Inc., Waltham, MA, USA). The absorbance of the standard solution and the rutin standard curve were calculated. Subsequently, $0.01 \mathrm{~g}$ of AJWTF extract was dissolved in $5 \mathrm{~mL}$ of $90 \%$ ethanol, and $2 \mathrm{~mL}$ of AJWTF extract solution was poured into a $25-\mathrm{mL}$ volumetric flask. The flavonoid content in the AJWTF extract was determined using the repeated rutin standard curve method (rutin meter) [14].

\subsection{Establishment of Alcohol-Induced Gastric Injury Model in Mice}

Specific pathogen-free (SPF) Kunming mice aged 6 weeks (male, body weight $20 \pm 2$ g) were purchased from Chongqing Medical University and fed with mouse basic feed and drinking water; the bedding material was changed once every two days for one week. The mice were divided into five groups with 10 mice each: the normal group, model group, low concentration AJWTF group (AJWTF-L group), high concentration AJWTF group (AJWTF-H group), and ranitidine group. The normal and model groups were given normal saline by gastric perfusion; the AJWTF-L and AJWTF-H mice were given 100 and $200 \mathrm{mg} / \mathrm{kg}$ AJWTF via gastric perfusion, respectively; the ranitidine group was given $50 \mathrm{mg} / \mathrm{kg}$ ranitidine for 14 days via gastric perfusion, and all experimental mice were fasted for $24 \mathrm{~h}$ on day 14. On day 15, all mice, except for those in the normal group, received an ethanol mixture (60\% ethanol, $40 \% 150 \mathrm{mmol} / \mathrm{L}$ hydrochloric acid) $1 \mathrm{~h}$ after gastric administration, with $0.1 \mathrm{~mL}$ of ethanol mixture per $10 \mathrm{~g}$ of mouse body weight [15]. After intragastric administration for $30 \mathrm{~min}$, blood from the eyeball was collected, and gastric tissue was dissected for use. The volume and $\mathrm{pH}$ of the gastric juice were measured (pH meter, PHS-25, Shanghai INESA Scientific Instrument Co., Ltd., Shanghai, China), while the degree of gastric mucosal injury was assessed intuitively. The inhibitory rate of gastric injury $(\%)=(1-$ area of gastric injury / area of gastric tissue $) \times 100 \%$ was calculated using the inhibitory rate of the gastric injury after pictures were taken. The protocol for these experiments was approved by the Animal Ethics Committee of Chongqing Collaborative Innovation Center for Functional Food (201802003B) on February 22, 2018.

\subsection{Determination of Superoxide Dismutase and Glutathione Activities and Malondialdehyde Level in Serum}

Blood was kept at room temperature for $1 \mathrm{~h}$; then, the blood was centrifuged at $4000 \mathrm{rpm}$ for $10 \mathrm{~min}$, the upper limit of the serum was measured, and the superoxide dismutase (SOD), glutathione (GSH), and malondialdehyde (MDA) levels in the mouse serum were determined in accordance with the instructions provided in the superoxide dismutase (SOD) assay kit (WST-1 method), glutathione 
(GSH) assay kit (spectrophotometric method) and malondialdehyde (MDA) assay kit (TBA method) (Nanjing Jiancheng Bioengineering Institute, Nanjing, Jiangsu, China) [16].

\subsection{Determination of Superoxide Dismutase and Glutathione Activities and Malondialdehyde Level in Gastric} Tissue

Mouse liver was used to prepare $10 \%$ homogenate, which was then centrifuged at $4000 \mathrm{rpm}$ for $10 \mathrm{~min}$. The supernatant was taken out, and the SOD, GSH, and MDA levels in gastric tissues were determined in accordance with the instructions accompanying the kits (Nanjing Jiancheng Bioengineering Institute, Nanjing, Jiangsu, China) [16].

\subsection{Pathological Observation of Gastric Tissue}

About $0.5 \mathrm{~cm}^{2}$ mouse gastric tissue was immobilized in $10 \%$ formalin solution for $48 \mathrm{~h}$. The gastric tissue was dehydrated, transparent, waxed, embedded, and sectioned. Hematoxylin and eosin staining was performed to observe the morphological changes under an optical microscope.

\subsection{Quantitative Polymerase Chain Reaction Assay}

Gastric tissues of mice were crushed, and total RNA was extracted from the gastric tissues with the use of RNAzol. The concentration of the total RNA was then diluted to $1 \mu \mathrm{g} / \mu \mathrm{L}$. The diluted total RNA solution of $5 \mu \mathrm{L}$ was then taken out, and the reverse transcription kit was used to obtain the template of the DNA. Then, $2 \mu \mathrm{L}$ of DNA template was mixed with $10 \mu \mathrm{L}$ of SYBR Green PCR Master Mix and primers $\left(1 \mu \mathrm{L}\right.$ of forward and $1 \mu \mathrm{L}$ of reverse), and then reacted at $95^{\circ} \mathrm{C}$ for $60 \mathrm{~s}$. Forty cycles were performed at $95^{\circ} \mathrm{C}$ for $15 \mathrm{~s}, 55^{\circ} \mathrm{C}$ for $30 \mathrm{~s}$, and $72{ }^{\circ} \mathrm{C}$ for $35 \mathrm{~s}$. Gene expression (Table 1) was then detected at $95^{\circ} \mathrm{C}$ for $30 \mathrm{~s}$ and $55^{\circ} \mathrm{C}$ for $35 \mathrm{~s}$. Glyceraldehyde-3-phosphate dehydrogenase (GAPDH) was used as the internal reference, and the relative expression of the gene was calculated using the $2^{-\Delta \Delta C t}$ method [17].

Table 1. Sequences of primers used in this study.

\begin{tabular}{cl}
\hline Gene Name & \multicolumn{1}{c}{ Sequence } \\
\hline nNOS & $\begin{array}{l}\text { Forward: 5'-GAATACCAGCCTGATCCATGGAA-3' } \\
\text { Reverse: 5'-TCCTCCAGGAGGGTGTCCACCGCATG-3' }\end{array}$ \\
\hline \multirow{2}{*}{ eNOS } & $\begin{array}{l}\text { Forward: 5'-TCAGCCATCACAGTGTTCCC-3' } \\
\text { Reverse: 5'-ATAGCCCGCATAGCGTATCAG-3' }\end{array}$ \\
\hline iNOS & $\begin{array}{l}\text { Forward: 5'-GTTCTCAGCCCAACAATACAAGA-3' } \\
\text { Reverse: 5'-GTGGACGGGTCGATGTCAC-3' }\end{array}$ \\
\hline Cu/Zn-SOD & $\begin{array}{l}\text { Forward: 5'-AACCAGTTGTGTTGTCAGGAC-3' } \\
\text { Reverse: 5'-CCACCATGTTTCTTAGAGTGAGG-3' }\end{array}$ \\
\hline \multirow{2}{*}{ Mn-SOD } & $\begin{array}{l}\text { Forward: 5'-CAGACCTGCCTTACGACTATGG-3' } \\
\text { Reverse: 5'-CTCGGTGGCGTTGAGATTGTT-3' }\end{array}$ \\
\hline CAT & $\begin{array}{l}\text { Forward: 5'-GGAGGCGGGAACCCAATAG-3' } \\
\text { Reverse: 5'-GTGTGCCATCTCGTCAGTGAA-3' }\end{array}$ \\
\hline GAPDH & Forward: 5'-AGGTCGGTGTGAACGGATTTG-3' \\
& Reverse: 5'-GGGGTCGTTGATGGCAACA-3' \\
\hline
\end{tabular}

nNOS: Neuronal nitric oxide synthase; eNOS: Endothelial nitric oxide synthase; iNOS: Inducible nitric oxide synthase; Cu/Zn-SOD: Copper/zinc superoxide dismutase; Mn-SOD: Manganese superoxide dismutase; CAT: Catalase; GAPDH: Glyceraldehyde-3-phosphate dehydrogenase.

\subsection{Statistical Analysis}

Three parallel experiments were conducted on the serum and tissue indexes of each mouse, and the average values were obtained. The data were analyzed using the SAS 9.1 statistical software 
(SAS Institute, Inc., Cary, NC, USA) [13]. One-way analysis of variance (ANOVA) was used to analyze whether significant differences existed among the groups at the level of $p<0.05$.

\section{Results}

\subsection{Content of Anji White Tea Flavonoid Extracts}

The regression equation of the standard curve of the rutin standard solution was $Y=842.34 X$ +0.1509 , where $Y$ is the concentration of the rutin standard solution, and $X$ is the absorbance value. According to the standard curve calculation, the purity of flavonoids in AJWTF extracts reached $68.3 \%$ (rutin calculation), which proved that flavonoids were the main components in the follow-up animal experiments.

\subsection{Volume and $p H$ of Gastric Juice in Mice}

Table 2 shows that the model group exhibited the largest gastric juice volume and the lowest $\mathrm{pH}$, whereas the normal group exhibited the lowest volume and the highest $\mathrm{pH}$. Both the AJWTF and ranitidine decreased the volume and increased the $\mathrm{pH}$ of gastric juice in mice with gastric injury, relative to those in the model group. The effect of AJWTF-H was similar to that that of ranitidine; that is, AJWTF-H and ranitidine could significantly $(p<0.05)$ reduce gastric juice volume and increase gastric juice $\mathrm{pH}$ in mice with gastric injury compared with AJWTF-L. Anji white tea flavonoids could effectively reduce the increase in volume and decrease in $\mathrm{pH}$ of gastric juice as a result of gastric injury.

Table 2. Volume and $\mathrm{pH}$ of gastric fluid in mice from each group $(n=10)$.

\begin{tabular}{ccc}
\hline Group & Gastric Juice Volume $(\mathbf{m L})$ & Gastric Juice $\mathbf{p H}$ \\
\hline Normal & $0.01 \pm 0.01^{\mathrm{b}}$ & $3.90 \pm 0.17^{\mathrm{a}}$ \\
Model & $0.22 \pm 0.03^{\mathrm{a}}$ & $1.91 \pm 0.11^{\mathrm{d}}$ \\
Ranitidine & $0.13 \pm 0.03^{\mathrm{ab}}$ & $2.52 \pm 0.12^{\mathrm{b}}$ \\
AJWTF-L & $0.19 \pm 0.04^{\mathrm{ab}}$ & $2.10 \pm 0.15^{\mathrm{c}}$ \\
AJWTF-H & $0.15 \pm 0.02^{\mathrm{ab}}$ & $2.31 \pm 0.14^{\mathrm{bc}}$ \\
\hline
\end{tabular}

Values presented are the means \pm standard deviation. ${ }^{\mathrm{a}-\mathrm{d}}$ Mean values with different letters in the same column indicate significant difference $(p<0.05)$ according to Duncan's multiple-range test. Ranitidine: Ranitidine at $50 \mathrm{mg} / \mathrm{kg}$ body weight (b.w.) by gavage; AJWTF-L: Anji white tea flavonoids at $100 \mathrm{mg} / \mathrm{kg}$ b.w. by gavage; AJWTF-H: Anji white tea flavonoids at $200 \mathrm{mg} / \mathrm{kg}$ b.w. by gavage.

\subsection{Gastric Damage Area and Inhibitory Rate of Anji White Tea Flavonoids in Mice}

Figure 1 and Table 3 show that ethanol causes a large area of gastric mucosal damage. Anji white tea flavonoids and ranitidine could significantly reduce the area of gastric mucosal damage $(p<0.05)$. The effect of AJWTF-H was stronger than that of AJWTF-L but slightly weaker than that of ranitidine. Owing to the AJWTF and ranitidine, the inhibition rate of AJWTF-H on gastric mucosal injury was also significantly higher than that of AJWTF-L $(p<0.05)$ and slightly lower than that of ranitidine. Anji white tea flavonoids could effectively reduce the area of alcohol-induced gastric mucosal damage and the degree of gastric injury. 


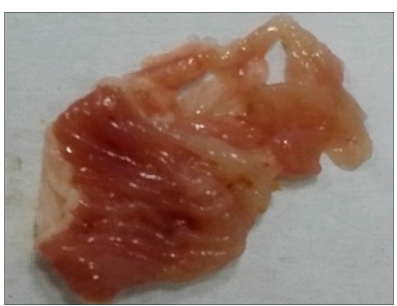

Normal

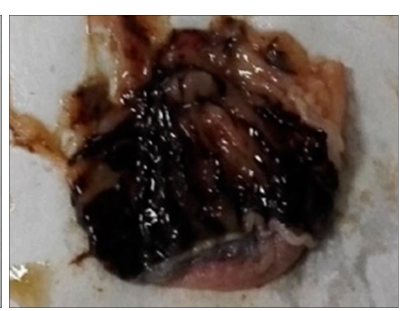

Model

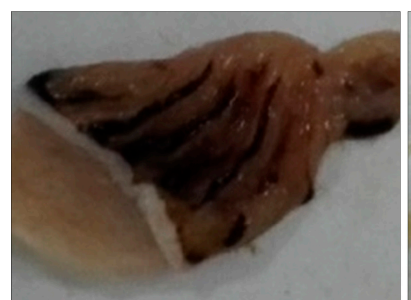

Ranitidine

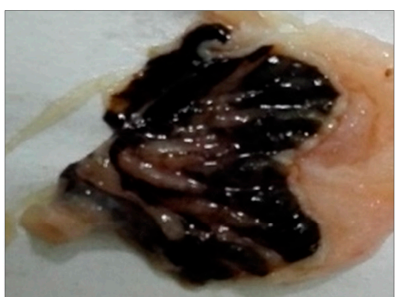

AJWTF-L

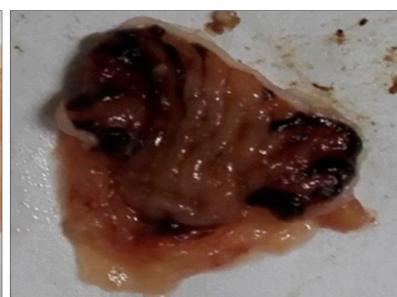

AJWTF-H

Figure 1. Stomach specimens of mice from each group. Ranitidine: Ranitidine at $50 \mathrm{mg} / \mathrm{kg}$ body weight (b.w.) by gavage; AJWTF-L: Anji white tea flavonoids at $100 \mathrm{mg} / \mathrm{kg}$ b.w. by gavage; AJWTF-H: Anji white tea flavonoids at $200 \mathrm{mg} / \mathrm{kg}$ b.w. by gavage.

Table 3. Degrees of gastric injury in mice of each group $(n=10)$.

\begin{tabular}{ccc}
\hline Group & Area of Gastric Injury $\left(\mathbf{m m}^{\mathbf{2}}\right)$ & Inhibitory Rate of Gastric Injury (\%) \\
\hline Normal & $0.00 \pm 0.00^{\mathrm{e}}$ & $100 \pm 0.00^{\mathrm{a}}$ \\
Model & $20.56 \pm 5.29^{\mathrm{a}}$ & - \\
Ranitidine & $1.98 \pm 0.62^{\mathrm{d}}$ & $90.37 \pm 5.86^{\mathrm{b}}$ \\
AJWTF-L & $13.44 \pm 1.57^{\mathrm{b}}$ & $34.63 \pm 3.48^{\mathrm{d}}$ \\
AJWTF-H & $3.76 \pm 1.65^{\mathrm{c}}$ & $81.71 \pm 2.12^{\mathrm{c}}$ \\
\hline
\end{tabular}

Values presented are the means \pm standard deviation. ${ }^{\mathrm{a}-\mathrm{e}}$ Mean values with different letters in the same column indicate significant difference $(p<0.05)$ according to Duncan's multiple-range test. Ranitidine: Ranitidine at $50 \mathrm{mg} / \mathrm{kg}$ body weight (b.w.) by gavage; AJWTF-L: Anji white tea flavonoids at $100 \mathrm{mg} / \mathrm{kg}$ b.w. by gavage; AJWTF-H: Anji white tea flavonoids at $200 \mathrm{mg} / \mathrm{kg}$ b.w. by gavage.

\subsection{Pathological Observation of Gastric Tissue in Mice}

As shown in Figure 2, the structure of gastric tissue in normal mice was intact, the cells were tightly arranged and orderly, the cells were of the same size, and the surface epithelium was intact and did not fall off. In the model group, the gastric tissue structure was incomplete, the number of cells decreased markedly, and the arrangement of cells was completely disrupted. The upper epidermis was exfoliated, and severe hemorrhage between the cells and tissues was observed. In the AJWTF-L group, the gastric cells were inconsistent in size and loosely arranged; part of the cell was damaged, and those with hyperemia and hemorrhage were exfoliated to a certain extent. Compared with the AJWTF-L mice, the AJWTF-H mice showed a more normal cell arrangement and tightness, more complete upper epidermis, and less congestion and hemorrhage. In the ranitidine group, the cells in gastric tissue were tightly arranged, and only individual cells appeared scattered; mucosal exfoliation was not obvious, and the cells and tissues were only slightly congested. The results indicated that AJWTF could protect gastric tissues and prevent ethanol-induced damage; in addition, a large dose was better than a small dose. 


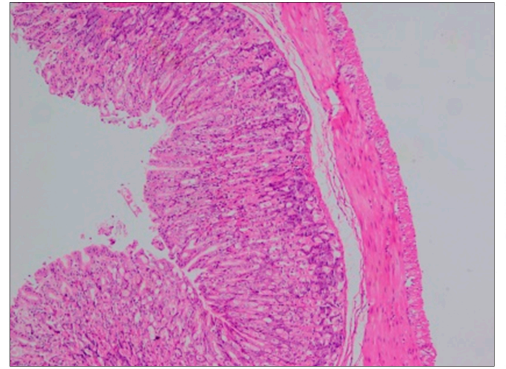

Normal

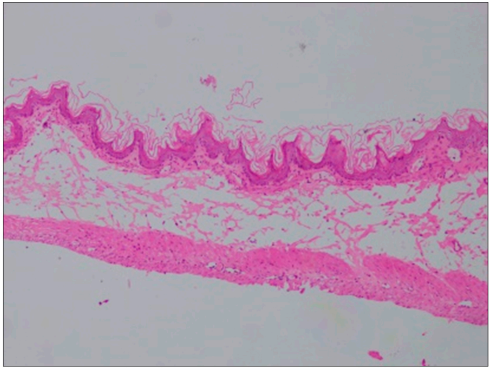

Model

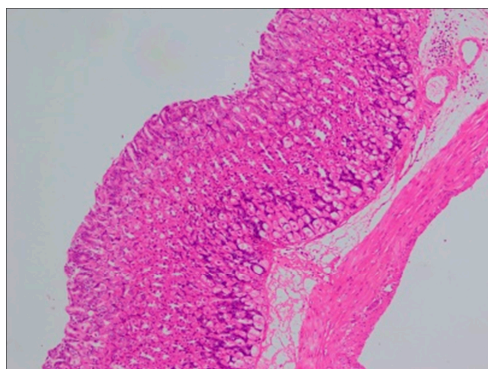

Ranitidine

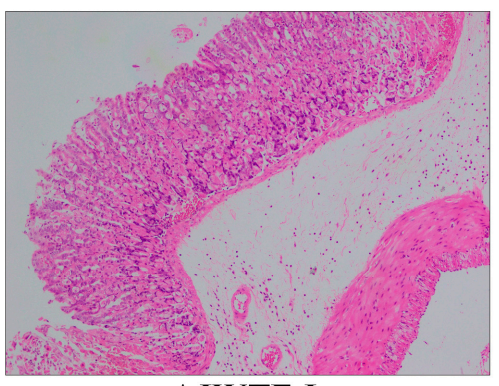

AJWTF-L

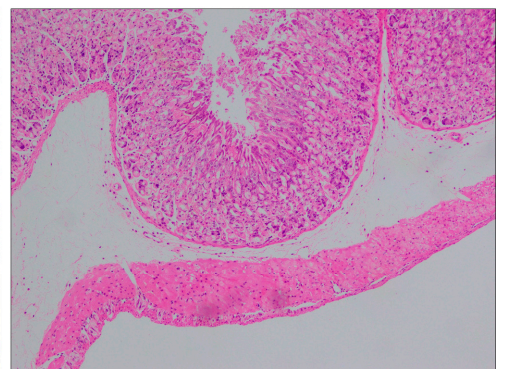

AJWTF-H

Figure 2. Hematoxylin and eosin-stained stomach sections of mice from each group $(100 \times)$. Ranitidine: Ranitidine at $50 \mathrm{mg} / \mathrm{kg}$ body weight (b.w.) by gavage; AJWTF-L: Anji white tea flavonoids at $100 \mathrm{mg} / \mathrm{kg}$ b.w. by gavage; AJWTF-H: Anji white tea flavonoids at $200 \mathrm{mg} / \mathrm{kg}$ b.w. by gavage.

3.5. Superoxide Dismutase and Glutathione Activities and Malondialdehyde Level in Mouse Serum and Gastric Tissues

Tables 4 and 5 show that the model group exhibited the lowest SOD and GSH activities and the highest MDA level in gastric tissues. The gastric tissues of mice in the normal group showed the opposite trend. The SOD and GSH activities in gastric tissues were the highest, whereas the MDA levels were the lowest. Anji white tea flavonoids could significantly increase the SOD and GSH activities in the gastric tissue of mice with gastric injury $(p<0.05)$ and decrease the MDA level $(p<0.05)$. The higher the AJWTF concentration was, the more obvious the effect and the closer it was to that of ranitidine.

Table 4. Serum levels of superoxide dismutase (SOD), glutathione (GSH), and malondialdehyde (MDA) in mice from each group $(n=10)$.

\begin{tabular}{cccc}
\hline Group & SOD $(\mathbf{U} / \mathbf{m L})$ & GSH $(\mathbf{m g} / \mathbf{L})$ & MDA $(\mathbf{n m o l} / \mathbf{m L})$ \\
\hline Normal & $155.595 \pm 3.669^{\mathrm{a}}$ & $19.112 \pm 0.890^{\mathrm{a}}$ & $6.000 \pm 0.003^{\mathrm{c}}$ \\
Model & $61.732 \pm 11.933^{\mathrm{e}}$ & $8.8789 \pm 0.261^{\mathrm{e}}$ & $10.667 \pm 1.670^{\mathrm{a}}$ \\
Ranitidine & $137.679 \pm 8.663^{\mathrm{b}}$ & $18.209 \pm 0.987^{\mathrm{b}}$ & $6.444 \pm 1.031^{\mathrm{ab}}$ \\
AJWTF-L & $95.032 \pm 7.944^{\mathrm{d}}$ & $10.233 \pm 0.952^{\mathrm{d}}$ & $9.222 \pm 0.956^{\mathrm{a}}$ \\
AJWTF-H & $113.532 \pm 18.779^{\mathrm{ac}}$ & $13.243 \pm 0.426^{\mathrm{c}}$ & $7.556 \pm 0.685^{\mathrm{ab}}$ \\
\hline
\end{tabular}

Values presented are the means \pm standard deviation. ${ }^{\text {a-e }}$ Mean values with different letters in the same column indicate significant difference $(p<0.05)$ according to Duncan's multiple-range test. Ranitidine: Ranitidine at $50 \mathrm{mg} / \mathrm{kg}$ body weight (b.w.) by gavage; AJWTF-L: Anji white tea flavonoids at $100 \mathrm{mg} / \mathrm{kg}$ b.w. by gavage; AJWTF-H: Anji white tea flavonoids at $200 \mathrm{mg} / \mathrm{kg}$ b.w. by gavage. 
Table 5. Superoxide dismutase (SOD) and glutathione (GSH) activities and malondialdehyde (MDA) level in stomach tissues of mice from each group $(n=10)$.

\begin{tabular}{cccc}
\hline Group & SOD (U/mg protein) & GSH (mg/g protein) & MDA (nmol/mg protein) \\
\hline Normal & $62.42 \pm 2.880^{\mathrm{a}}$ & $10.106 \pm 0.184^{\mathrm{a}}$ & $0.460 \pm 0.069^{\mathrm{d}}$ \\
Model & $30.17 \pm 0.820$ & $3.956 \pm 0.577^{\mathrm{d}}$ & $0.753 \pm 0.059^{\mathrm{a}}$ \\
Ranitidine & $60.42 \pm 2.220^{\mathrm{a}}$ & $9.232 \pm 0.913^{\mathrm{a}}$ & $0.486 \pm 0.059^{\mathrm{cd}}$ \\
AJWTF-L & $40.33 \pm 2.260^{\mathrm{c}}$ & $6.196 \pm 0.752^{\mathrm{c}}$ & $0.691 \pm 0.040^{\mathrm{b}}$ \\
AJWTF-H & $52.11 \pm 3.780^{\mathrm{b}}$ & $8.119 \pm 0.773^{\mathrm{b}}$ & $0.582 \pm 0.065^{\mathrm{c}}$ \\
\hline
\end{tabular}

Values presented are the means \pm standard deviation. ${ }^{a-d}$ Mean values with different letters in the same column indicate significant difference $(p<0.05)$ according to Duncan's multiple-range test. Ranitidine: Ranitidine at 50 $\mathrm{mg} / \mathrm{kg}$ body weight (b.w.) by gavage; AJWTF-L: Anji white tea flavonoids at $100 \mathrm{mg} / \mathrm{kg}$ b.w. by gavage; AJWTF-H: Anji white tea flavonoids at $200 \mathrm{mg} / \mathrm{kg}$ b.w. by gavage.

\subsection{Expression of nNOS, eNOS, and iNOS Messenger RNA in Gastric Tissue of Mice}

Figure 3 shows that the expression levels of neuronal nitric oxide synthase (nNOS), endothelial nitric oxide synthase (eNOS), and inducible nitric oxide synthase (iNOS) were lowest in the model group. After AJWTF treatment, the expression levels of nNOS and eNOS in gastric tissues of mice with gastric injury increased significantly $(p<0.05)$, whereas that of iNOS decreased significantly $(p<0.05)$. The effect of AJWTF-H was stronger than that of AJWTF-L and similar to that of ranitidine.
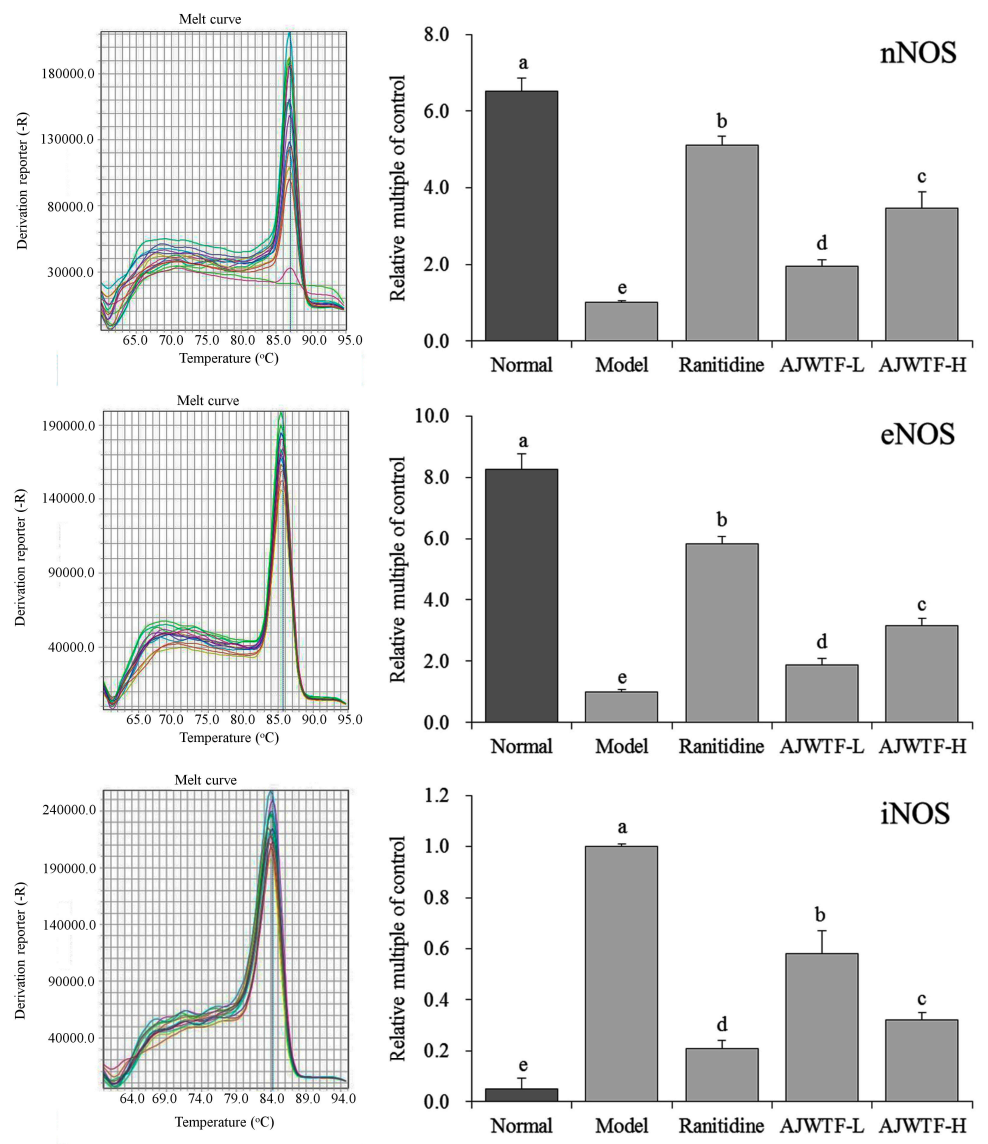

Figure 3. Messenger RNA expression of neuronal nitric oxide synthase (nNOS), endothelial nitric oxide synthase (eNOS), and inducible nitric oxide synthase (iNOS) in the stomach tissues of mice from each group. Values presented are the means \pm standard deviation. ${ }^{\mathrm{a}-\mathrm{c}}$ Mean values with different letters in the same bars indicate significant difference $(p<0.05)$ according to Duncan's multiple-range test. Ranitidine: Ranitidine at $50 \mathrm{mg} / \mathrm{kg}$ body weight (b.w.) by gavage; AJWTF-L: Anji white tea flavonoids at $100 \mathrm{mg} / \mathrm{kg}$ b.w. by gavage; AJWTF-H: Anji white tea flavonoids at $200 \mathrm{mg} / \mathrm{kg}$ b.w. by gavage. 
3.7. Expression of $\mathrm{Cu} / \mathrm{Zn}$-Superoxide Dismutase, Mn-Superoxide Dismutase, and Catalase Messenger RNA in Gastric Tissues of Mice

Figure 4 shows that the highest expression of $\mathrm{Cu} / \mathrm{Zn}-\mathrm{SOD}, \mathrm{Mn}-\mathrm{SOD}$, and catalase (CAT) was observed in the liver tissues of mice in the normal group. The expression of $\mathrm{Cu} / \mathrm{Zn}-\mathrm{SOD}, \mathrm{Mn}-\mathrm{SOD}$, and CAT in gastric tissues was significantly reduced by ethanol-induced gastric injury $(p<0.05)$. Both AJWTF and ranitidine could significantly inhibit the expression of $\mathrm{Cu} / \mathrm{Zn}-\mathrm{SOD}, \mathrm{Mn}-\mathrm{SOD}$, and CAT in ethanol-induced gastric tissue injury $(p<0.05)$. With increasing concentration, AJWTF increased the expression of $\mathrm{C} / \mathrm{Zn}-\mathrm{SOD}, \mathrm{Mn}-\mathrm{SOD}$, and CAT in gastric tissues. The higher the expression of $\mathrm{Cu} / \mathrm{Zn}-\mathrm{SOD}, \mathrm{Mn}-\mathrm{SOD}$, and CAT was, the closer the effect exerted by AJWTF-H was to that of ranitidine.
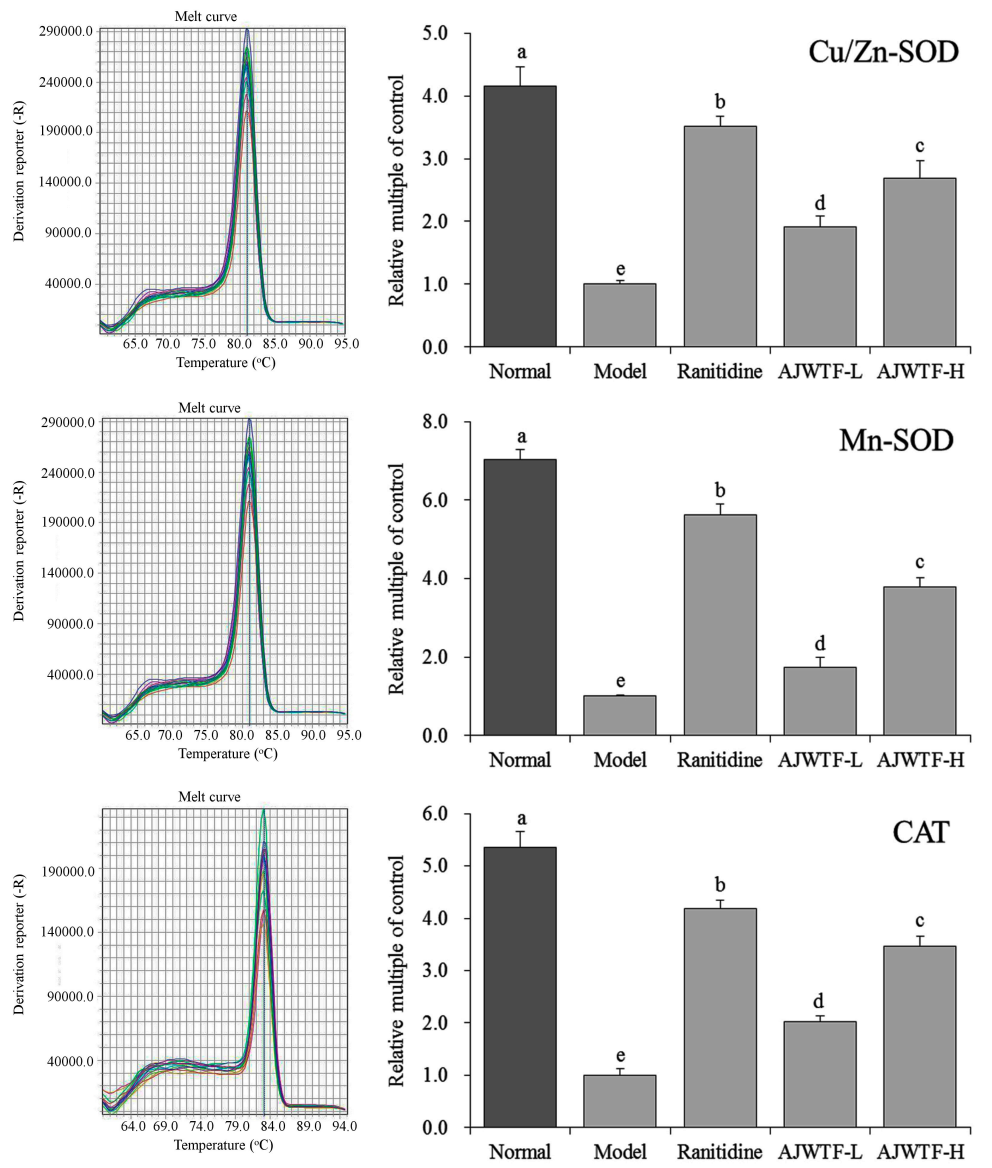

Figure 4. Messenger RNA expression of copper/zinc superoxide dismutase (Cu/Zn-SOD), manganese SOD (Mn-SOD), and catalase (CAT) in the stomach tissues of mice from each group. Values presented are the means \pm standard deviation. ${ }^{\mathrm{a}-\mathrm{c}}$ Mean values with different letters in the same bars indicate significant difference $(p<0.05)$ according to Duncan's multiple-range test. Ranitidine: Ranitidine at $50 \mathrm{mg} / \mathrm{kg}$ body weight (b.w.) by gavage; AJWTF-L: Anji white tea flavonoids at $100 \mathrm{mg} / \mathrm{kg}$ b.w. by gavage; and AJWTF-H: Anji white tea flavonoids at $200 \mathrm{mg} / \mathrm{kg}$ b.w. by gavage.

\section{Discussion}

The alcohol-induced gastric injury model is used to test human gastric acid secretion and simulate alcohol-induced acute digestive injury. Modeling of the damage helps assess whether potential bioactive substances exert protective and antioxidant effects on gastric tissues [18]. Ethanol/hydrochloric acid solution can be used to observe the ulceration of gastric mucosa in mice after gastric administration. The area of ulceration can be used to directly determine the degree of gastric injury by using related indicators [19]. 
Unlike infectious diseases, gastric injury is multifactorial and develops through different contacts. Different risk factors and unhealthy lifestyle are identified as the main causes. Ethanol is regarded as an important factor inducing human gastric injury mainly because the gastric mucosa is easy to penetrate and destroy, exposing it to gastric acid and pepsinase [20]. Under the combined action of gastric acid and pepsinase, severe vasoconstriction can occur within a short time, accompanied by rapid dilation of small arteries. These reactions of blood vessels promote vascular injury and ultimately lead to the formation of gastric injury [21]. In the current study, AJWTF could effectively reduce the area of ethanol/hydrochloric acid-induced gastric injury and protect the gastric mucosa. The inhibition rate of gastric injury in the AJWTF group was similar to that in the normal group and the ranitidine group, indicating that AJWTF prevented the gastric injury to a certain extent.

Normally, gastric juice does not affect the gastric mucosa. After gastric mucosal injury, the stomach is stimulated and secretes a large amount of gastric acid, thus increasing the volume of gastric juice in the stomach and decreasing the $\mathrm{pH}$ of gastric juice. These effects aggravate the damage to the gastric mucosa, exacerbating the gastric injury, which then leads to a vicious circle [22]. In the current study, AJWTF could effectively decrease the volume of gastric juice and increase the $\mathrm{pH}$ of gastric juice in mice with gastric injury, thus protecting the gastric tissues and alleviating alcoholic gastric injury.

Meanwhile, nNOS, eNOS, and iNOS represent the neuronal type, endothelial type, and inducible type of NOS, respectively. Nitric oxide synthase is the rate-limiting enzyme of NO synthesis and widely exists in the normal tissues of humans and animals [23]. Under normal physiological conditions, the mechanism of NO production, release, diffusion, and inactivation is precisely regulated in the nervous system, which is mainly achieved by regulating the activation and deactivation of nNOS [24]. Neuronal NOS not only plays an important role in the nervous system but is also distributed in gastric mucosal epithelial cells. Neuronal NOS regulates blood flow and muscle contraction by regulating NO to control the degree of gastric injury [25]. The decrease in nNOS expression can aggravate gastric tissue damage [26]. The expression and activity of eNOS are relatively stable. Nitric oxide derived from eNOS mainly participates in promoting epithelial repair, regulating gastric mucosal blood flow and adaptive cell protection, inhibiting gastric acid secretion, enhancing mucus barrier function, and promoting vascular regeneration [27]. Simultaneously, eNOS can inhibit the oxidative damage of blood vessels caused by oxidative stress, as well as relax and protect blood vessels [28]. Once iNOS is activated, enzyme activity continues for an extended time and produces NO in large quantities. Low NO concentration can effectively resist gene mutation and activate the defense mechanism of the body, whereas high NO concentrations can lead to loss of control of gene mutation, thus stimulating gene mutation and aggravating tissue damage [29]. Anji white tea flavonoids can promote nNOS and eNOS expression in the gastric tissues of mice with gastric injury, as well as reduce the expression of iNOS to inhibit inflammatory response and protect gastric mucosa, thus inhibiting gastric injury. Oxidative stress is the main characteristic of gastric mucosal injury. Damage to gastric mucosal cells is aggravated by the decrease in antioxidants, such as SOD, CAT, and GSH, as well as the increase in free radicals after ethanol treatment [30]. As a response to free-radical accumulation, SOD and other cell antioxidant enzymes are considered the first line of defense against oxidative damage [31]. In addition, CAT and GSH exert similar effects, which can eventually clear free radicals in the body, maintain the balance between oxidation and antioxidation, and protect the body from free radical damage; thus, the content of antioxidant enzymes can directly reflect the number of free radicals in the body [32,33]. $\mathrm{Cu} / \mathrm{Zn}-\mathrm{SOD}$ is mainly found in the cytoplasm, whereas Mn-SOD is typically present in mitochondria. $\mathrm{Cu} / \mathrm{Zn}-\mathrm{SOD}$ and $\mathrm{Mn}-\mathrm{SOD}$ sensitivity to different factors varies [34]. After ethanol-induced gastric mucosal injury, the SOD, CAT, and GSH activities in the body decrease significantly $[17,35]$. The reduced activity of antioxidant enzymes may trigger chain lipid peroxidation, resulting in the decreased fluidity and enhanced permeability of biofilms [36]. Malondialdehyde is produced by lipid decomposition of peroxide; thus, the MDA level is often used as a marker of lipid peroxidation and reacts as free radicals are produced [37]. In the present study, the SOD and GSH activities in the serum and gastric tissues of the AJWTF-treated mice with gastric damage were 
significantly higher than those of the model group. In addition, the MDA content was significantly lower in the AJWTF group than in the model group. Further experiments confirmed that AJWTF could upregulate the expression of $\mathrm{Cu} / \mathrm{Zn}-\mathrm{SOD}, \mathrm{Mn}-\mathrm{SOD}$, and CAT in the gastric tissues of mice with gastric injury. The results indicated that AJWTF could reduce the free radical damage caused by ethanol and lipid peroxidation protecting the balance of antioxidant in vivo to inhibit alcohol-induced gastric injury. Rutin has a strong antioxidant effect, which can inhibit the damage and aggravation of gastric mucosa caused by oxidative stress [38]. At the same time, rutin can inhibit the excessive production of NO caused by inflammation, thus inhibiting the increase of iNOS activity in gastric mucosa, while increasing the activity of constitutive NOS (cNOS), inhibiting lymphocyte infiltration in gastric mucosa tissue and playing a protective role in gastric mucosa [39]. The preventive effect of AJWTF on gastric injury may also be due to this mechanism.

\section{Conclusions}

In this study, AJWTFs were used to treat mice with gastric injury, and corresponding indexes of serum and gastric tissues were determined. The results indicated that AJWTFs could (i) significantly repair the abnormal indexes caused by gastric injury, (ii) regulate oxidative stress in serum and gastric tissues to achieve close to normal levels, and (iii) control the expression of related genes in gastric tissues to reach almost normal levels, thereby restoring the effect of gastric injury on gastric tissues. The results showed that AJWTFs exerted a positive effect on the repair and prevention of gastric injury, and its intensity depended on AJWTF concentration. With an increase in AJWTF concentration, the preventive effect of AJWTFs on gastric injury was enhanced. Moreover, $200 \mathrm{mg} / \mathrm{kg}$ AJWTF could achieve nearly the same effect as that of ranitidine. Therefore, AJWTFs can be used and developed as active substances to prevent alcohol-induced gastric injury, particularly as functional foods to counter the effect of alcohol or for the repair of chronic alcohol-induced gastric injury.

Author Contributions: B.L. and X.F., performed the majority of the experiments and wrote the manuscript; J.Z. and Y.W., contributed to the data analysis; X.Z. designed and supervised the study and checked the final manuscript.

Funding: This research was funded by the Program for Innovation Team Building at Institutions of Higher Education in Chongqing (CXTDX201601040), the Introduction of High-level Personnel Research Start-up Fund of Chongqing University of Education (2013BSRC001), the Scientific Research Foundation for Returned Overseas Chinese Scholars, and the State Education Ministry (Jiaowaisiliu (2014)1685), China.

Conflicts of Interest: The authors declare no conflicts of interest.

\section{References}

1. Zima, T.; Fialová, L.; Mestek, O.; Janebová, M.; Crkovská, J.; Malbohan, I.; Stípek, S.; Mikulíková, L.; Popov, P. Oxidative stress, metabolism of ethanol and alcohol-related diseases. J. Biomed. Sci. 2001, 8, 59-70. [CrossRef] [PubMed]

2. Salim, A.S. Protection against stress-induced acute gastric mucosal injury by free radical scavengers. Intensive Care Med. 1991, 17, 455-460. [CrossRef] [PubMed]

3. Chang, W.; Bai, J.; Tian, S.; Ma, M.; Li, W.; Yin, Y.; Deng, R.; Cui, J.; Li, J.; Wang, G.; Zhang, P.; Tao, K. Autophagy protects gastric mucosal epithelial cells from ethanol-induced oxidative damage via mTOR signaling pathway. Exp. Biol. Med. 2017, 242, 1025-1033. [CrossRef]

4. Xu, L.; Shi, P.T.; Fu, X.S.; Cui, H.F.; Ye, Z.H.; Cai, C.B.; Yu, X.P. Protected geographical indication identification of a Chinese green tea (Anji-white) by near-infrared spectroscopy and chemometric class modeling techniques. J. Spectrosc. 2013, 2013, 1-8. [CrossRef]

5. Kähkönen, M.P.; Heinonen, M. Antioxidant activity of anthocyanins and their aglycons. J. Agric. Food Chem. 2003, 51, 628-633. [CrossRef]

6. Zhang, W.; Dong, Z.; Chang, X.; Zhang, C.; Rong, G.; Gao, X.; Zeng, Z.; Wang, C.; Chen, Y.; Rong, Y.; et al. Protective effect of the total flavonoids from Apocynum venetum L. on carbon tetrachloride-induced hepatotoxicity in vitro and in vivo. J. Physiol. Biochem. 2018, 74, 301-312. [CrossRef] [PubMed] 
7. Huang, A. Advances in research of pharmacological action of flavonoids. Auhui Agri. Sci. Bull. 2007, 13, 71-72.

8. O'Reilly, J.D.; Mallet, A.I.; McAnlis, G.T.; Young, I.S.; Halliwell, B.; Sanders, T.A.; Wiseman, H. Consumption of flavonoids in onions and black tea: Lack of effect on F2-isoprostanes and autoantibodies to oxidized LDL in healthy humans. Am. J. Clin. Nutr. 2001, 73, 1040-1044. [CrossRef] [PubMed]

9. Yoshida, H.; Ishikawa, T.; Hosoai, H.; Suzukawa, M.; Ayaori, M.; Hisada, T.; Sawada, S.; Yonemura, A.; Higashi, K.; Ito, T.; et al. Inhibitory effect of tea flavonoids on the ability of cells to oxidize low density lipoprotein. Biochem. Pharmacol. 1999, 58, 1695-1703. [CrossRef]

10. Lee, H.L.; Kang, K.S. Protection effect of punicalagin isolated from pomegranate on inflammation and ethanol-induced gastric mucosal injury. Bull. Korean Chem. Soc. 2016, 37, 1778-1782. [CrossRef]

11. Elshazly, S.M.; Abd El Motteleb, D.M.; Ibrahim, I.A. Hesperidin protects against stress induced gastric ulcer through regulation of peroxisome proliferator activator receptor gamma in diabetic rats. Chem. Biol. Int. 2018, 291, 153-161. [CrossRef] [PubMed]

12. La Casa, C.; Villegas, I.; Alarcón de la Lastra, C.; Motilva, V.; Martín Calero, M.J. Evidence for protective and antioxidant properties of rutin, a natural flavone, against ethanol induced gastric lesions. J. Ethnopharmacol. 2000, 71, 45-53. [CrossRef]

13. Lv, N.; Zhang, W.Z.; Chen, L.L.; Zhang, J.; Shen, M.H. Antioxidant activity of flavonoids from Anji white tea in vitro. J. Toxicol. 2014, 28, 389-392.

14. Zhao, X.; Yi, R.; Sun, P.; Song, J. Improvement effects of Kuding tea flavonoids extracts on D-galactose induced mice aging. Sci. Technol. Food Ind. 2017, 38, 303-308. [CrossRef]

15. Mathews, S.; Xu, M.; Wang, H.; Bertola, A.; Gao, B. Animals models of gastrointestinal and liver diseases. Animal models of alcohol-induced liver disease: Pathophysiology, translational relevance, and challenges. Am. J. Physiol. Gastrointest. Liver Physiol. 2014, 306, 819-823. [CrossRef] [PubMed]

16. Yi, R.; Wang, R.; Sun, P.; Zhao, X. Antioxidant-mediated preventative effect of Dragon-pearl tea crude polyphenol extract on reserpine-induced gastric ulcers. Exp. Ther. Med. 2015, 10, 338-344. [CrossRef] [PubMed]

17. Zhao, X.; Qian, Y.; Li, G.J.; Tan, J. Preventive effects of the polysaccharide of Larimichthys crocea swim bladder on carbon tetrachloride $\left(\mathrm{CCl}_{4}\right)$-induced hepatic damage. Chin. J. Nat. Med. 2015, 13, 521-528. [CrossRef]

18. Madushani Herath, K.H.I.N.; Bing, S.J.; Cho, J.; Kim, A.; Kim, G.; Kim, J.S.; Kim, J.B.; Doh, Y.H.; Jee, Y. Sasa quelpaertensis leaves ameliorate alcohol-induced liver injury by attenuating oxidative stress in HepG2 cells and mice. Acta Histochem. 2018, 120, 477-489. [CrossRef]

19. Suo, H.; Zhao, X.; Qian, Y.; Sun, P.; Zhu, K.; Li, J.; Sun, B. Lactobacillus fermentum Suo attenuates $\mathrm{HCl} /$ ethanol induced gastric injury in mice through its antioxidant effects. Nutrients 2016, 8, 155. [CrossRef]

20. McDonough, K.H. Antioxidant nutrients and alcohol. Toxicology 2003, 189, 89-97. [CrossRef]

21. Araújo Júnior, R.F.; Garcia, V.B.; Leitão, R.F.; Brito, G.A.; Miguel Ede, C.; Guedes, P.M.; de Araújo, A.A. Carvedilol improves inflammatory response, oxidative stress and fibrosis in the alcohol-induced liver injury in rats by regulating Kuppfer cells and hepatic stellate cells. PLOS ONE 2016, 12, e0148868. [CrossRef]

22. Qian, Y.; Zhang, J.; Fu, X.; Yi, R.; Sun, P.; Zou, M.; Long, X.; Zhao, X. Preventive effect of raw Liubao tea polyphenols on mouse gastric injuries induced by $\mathrm{HCl}$ /ethanol via anti-oxidative stress. Molecules 2018, 23, 2848. [CrossRef] [PubMed]

23. Ignarro, L.J.; Byrns, R.E.; Sumi, D.; de Nigris, F.; Napoli, C. Pomegranate juice protects nitric oxide against oxidative destruction and enhances the biological actions of nitric oxide. Nitric Oxide 2006, 15, 93-102. [CrossRef] [PubMed]

24. Liu, H.B.; Huang, X.D.; Liu, M.H.; Shanguan, J.Y. Significance of NOS expressions in gastric carcinoma. Med. J. Nat. Defend. For. Northwest China 2002, 23, 115-117.

25. Zhao, X.; Sun, P.; Li, G.; Yi, R.; Qian, Y.; Park, K.Y. Polyphenols in Kuding tea help prevent $\mathrm{HCl} /$ ethanol-induced gastric injury in mice. Food Funct. 2018, 9, 1713-1725. [CrossRef]

26. Calatayud, S.; Ramírez, M.C.; Sanz, M.J.; Moreno, L.; Hernández, C.; Bosch, J.; Piqué, J.M.; Esplugues, J.V. Gastric mucosal resistance to acute injury in experimental portal hypertension. Br. J. Pharmacol. 2001, 132, 209-317. [CrossRef] [PubMed]

27. Shore, R.; Björne, H.; Omoto, Y.; Siemiatkowska, A.; Gustafsson, J.A.; Lindblad, M.; Holm, L. Sex differences and effects of oestrogen in rat gastric mucosal defence. World J. Gastroenterol. 2017, 23, 426-436. [CrossRef] 
28. Banerjee, M.; Vats, P. Reactive metabolites and antioxidant gene polymorphisms in type 2 diabetes mellitus. Redox Biol. 2013, 2, 170-177. [CrossRef] [PubMed]

29. Gottfredsen, R.H.; Larsen, U.G.; Enghild, J.J.; Petersen, S.V. Hydrogen peroxide induce modifications of human extracellular superoxide dismutase that results in enzyme inhibition. Redox Biol. 2013, 1, $24-31$. [CrossRef]

30. Chen, S.; Zhao, X.; Sun, P.; Qian, J.; Shi, Y.; Wang, R. Preventive effect of Gardenia jasminoides on $\mathrm{HCl} / \mathrm{ethanol}$ induced gastric injury in mice. J. Pharmacol. Sci. 2017, 133, 1-8. [CrossRef]

31. Ighodaro, O.M.; Akinloye, O.A. First line defence antioxidants-superoxide dismutase (SOD), catalase (CAT) and glutathione peroxidase (GPX): Their fundamental role in the entire antioxidant defence grid. Alex. J. Med. 2018, 54, 287-293. [CrossRef]

32. Kuo, K.L.; Weng, M.S.; Chiang, C.T.; Tsai, Y.J.; Lin-Shiau, S.Y.; Lin, J.K. Comparative studies on the hypolipidemic and growth suppressive effects of oolong, black, pu-erh, and green tea leaves in rats. J. Agric. Food Chem. 2005, 53, 480-489. [CrossRef] [PubMed]

33. Wong, J.Y.; Abdulla, M.A.; Raman, J.; Phan, C.W.; Kuppusamy, U.R.; Golbabapour, S.; Sabaratnam, V. Gastroprotective effects of Lion's mane mushroom Hericium erinaceus (Bull.:Fr.) Pers. (Aphyllophoromycetideae) extract against ethanol-induced ulcer in rats. Evid. Based Complement. Altern. Med. 2013, 2013, 492976. [CrossRef]

34. Bonthius, D.J., Jr.; Winters, Z.; Karacay, B.; Bousquet, S.L.; Bonthius, D.J. Importance of genetics in fetal alcohol effects: Null mutation of the nNOS gene worsens alcohol-induced cerebellar neuronal losses and behavioral deficits. Neurotoxicology 2015, 46, 60-72. [CrossRef]

35. Wu, X.; Huang, Q.; Xu, N.; Cai, J.; Luo, D.; Zhang, Q.; Su, Z.; Gao, C.; Liu, Y. Antioxidative and anti-inflammatory effects of water extract of Acrostichum aureum Linn. against ethanol-induced gastric ulcer in rats. Evid. Based Complement. Altern. Med. 2018, 2018, 3585394. [CrossRef]

36. Morin, M.P.; Bedran, T.B.; Fournier-Larente, J.; Haas, B.; Azelmat, J.; Grenier, D. Green tea extract and its major constituent epigallocatechin-3-gallate inhibit growth and halitosis-related properties of Solobacterium moorei. BMC Complement. Altern. Med. 2015, 15, 48. [CrossRef] [PubMed]

37. Pillai, S.; Oresajo, C.; Hayward, J. Ultraviolet radiation and skin aging: Roles of reactive oxygen species, inflammation and protease activation, and strategies for prevention of inflammation-induced matrix degradation-A review. Int. J. Cosmet. Sci. 2005, 27, 17-34. [CrossRef] [PubMed]

38. Olaleye, M.T.; Akinmoladun, A.C. Comparative gastroprotective effect of post-treatment with low doses of rutin and cimetidine in rats. Fundam. Clin. Pharmacol. 2013, 27, 138-145. [CrossRef] [PubMed]

39. Liu, Y.; Gou, L.; Fu, X.; Li, S.; Lan, N.; Yin, X. Protective effect of rutin against acute gastric mucosal lesions induced by ischemia-reperfusion. Pharm. Biol. 2013, 51, 914-919. [CrossRef] 